DOI 10.35381/cm.v7i1.539

\title{
Los derechos constitucionales en el debido proceso penal del sistema ecuatoriano
}

Constitutional rights in the criminal due process of the ecuadorian system

\author{
Pedro Pablo Perlaza-Espinoza \\ dq.pedroppe99@uniandes.edu.ec \\ Universidad Regional Autónoma de los Andes, Quevedo \\ Ecuador \\ https://orcid.org/0000-0002-6630-2402 \\ Luis Antonio Rivera-Velasco \\ uq.luisrivera@uniandes.edu.ec \\ Universidad Regional Autónoma de los Andes, Quevedo \\ Ecuador \\ https://orcid.org/0000-0003-2094-9566 \\ Orlando Iván Ronquillo-Riera \\ uq.orlandoronquillo@uniandes.edu.ec \\ Universidad Regional Autónoma de los Andes, Quevedo \\ Ecuador \\ https://orcid.org/0000-0001-6020-7255
}

Recibido: 01 de mayo de 2021

Aprobado: 01 de agosto de 2021 


\section{Estimado Editor (a):}

La vulneración de los derechos constitucionales en el debido proceso penal del sistema ecuatoriano actualmente, la persona sospechosa está obligado acercarse a la Fiscalía a rendir su versión, porque si no se acerca es llamado varías veces, incluso hasta obligándolo; haciendo uso de la fuerza pública. El debido proceso penal está formado por un conjunto de normas jurídicas que garantizan el equilibrio entre el Estado y sus ciudadanos, pues su fin primordial es hacer respetar los derechos fundamentales y evitar la arbitrariedad, por lo tanto todo funcionario público está obligado a respetar el principio de legalidad o reserva de ley mediante el cual se ha de entender que la única fuente de derecho nace de la ley, por tanto, el ciudadano tiene derecho a exigir del Estado que se respete este precepto constitucional. De esta forma, queda definido el debido proceso como un derecho de protección y un principio constitucional elemental, que regulan los derechos y garantías de las personas involucradas en los litigios penales. (Gutiérrez Campoverde, Cantos Ludeña, y Durán Ocampo, 2019, p.415).

Por lo tanto, el debido proceso es una garantía constitucional por la cual una correcta administración de justicia depende de la convivencia pacífica y la seguridad jurídica del país, y es el mecanismo de aplicación de los principios y garantías del derecho constitucional penal y procesal. El Debido Proceso es el más sofisticado instrumento de resolución de disputas y conflictos de contenido y relevancia jurídica, el proceso tiene reglas que permiten llegar a una resolución justa. El Estado tiene la potestad de sancionar a los infractores de la ley, por ejemplo, en el proceso penal; pero, tiene que brindarse al imputado un proceso en el cual se respeten las garantías constitucionales, esto es lo que permite calificar a un proceso como justo o debido.

Las garantías constituyen técnicas de protección diferentes a los derechos mismos, así lo establece la Constitución de la República del Ecuador de 2008, en su artículo 77, numeral 7, literal c, determina: 
Artículo 77. En todo proceso penal en que se haya privado de la libertad a una persona, se observarán las siguientes garantías básicas:

7. El derecho de toda persona a la defensa incluye:

c) Nadie podrá ser forzado a declarar en contra de sí mismo, sobre asuntos que puedan ocasionar su responsabilidad penal.

El cumplimiento estricto de las garantías constitucionales en el proceso penal, constituye uno de los pilares fundamentales para el ejercicio de la justicia, dentro de los paradigmas de la democracia contemporánea: la posibilidad de seguridad pública que se desprende de la persecución y juzgamientos penales, así como la aplicación de la pena, carece de significado verdadero, si no existe el marco idóneo para que tal alternativa ocupe dentro de la posibilidad de que quien esté siendo juzgado cuente con un espacio de realización en el ejercicio de sus derechos.

La alternativa para que se efectivicen tales garantías constitucionales en el proceso penal, se hace posible cuando los roles en el proceso penal sean acatados como manda la ley, y en la etapa preliminar o investigativa, el Juez penal cumpla con la tarea exclusiva de legalizar la investigación a cargo del ministerio público y la policía; y que el procesado cuente con la real posibilidad de ejercer los derechos inherentes a la necesidad de responder contra la incriminación que pesa sobre él. Lo que se necesita es que exista un marco propicio para la realización, y que la justicia cuente con un desarrollo lo menos unilateral y lo más integral posible, como el derecho a no ser obligado a declarar contra sí mismo ni a confesarse culpable. Continuando con este lineamiento, la Corte Constitucional del Ecuador (2014), sobre el debido proceso en la Sentencia № 005-16-SEP-CC caso № 1221-14-EP, señala:

El debido proceso es un derecho primordial que le asiste a las partes que se encuentran sometidas a un proceso judicial o administrativo; por tanto, existen garantías que deben ser observadas y aplicadas, con el objeto de que el proceso se constituya en un medio para la realización de la justicia. 
Por lo tanto, para Rodríguez Camacho (2018) es importante el apoyo mediante las garantías al respecto manifiesta:

Las garantías del debido proceso deben asegurar el acatamiento de los derechos y obligaciones de cualquier ámbito para beneficio de los ciudadanos, siendo la libertad uno de los derechos fundamentales más apreciados, es totalmente justificable la preocupación de los constituyentes por suministrar a los ciudadanos las garantías para su protección integral (p.35)

Es aquí cuando nos enfrentamos a un debate o un conflicto interno que surgen dentro del procesado, y del abogado defensor, ya que al establecerse estas garantías con las cuales, el Estado asegura la situación del procesado, se opta por acogerse al derecho al silencio creyendo que a través de este se podrá obtener resultados positivos, siendo en la mayoría de casos lo contrario, es decir el silencio queda fuera de los considerandos por los cuales el juez falla a favor o en contra de una de las partes.

Una mirada más amplia nos lleva a enmarcar este derecho a la no incriminación, dentro de la libertad a declarar del ciudadano o ciudadana, que plantea precisamente eso, libertades; es decir, contempla una visión distinta al sistema inquisitivo, en el que el procesado era considerado objeto de prueba, cambiando esta visión del derecho penal, a un sistema garantista, en el que en virtud del derecho a la no incriminación, conlleva a tratar al procesado como sujeto del proceso: un participante provisto de derechos independientes que toma parte en el proceso, es decir, en un sujeto activo del proceso. Para Benavides Benalcázar (2019, p.284) plantean "la víctima no es protegida únicamente dentro del ámbito judicial, sino que es el Estado y sus acciones concretas, mediante su institucionalidad y diversas competencias, quien debe atender su reparación durante y después de la sustanciación del proceso penal". Este papel de sujeto, hoy en día, está reafirmado; pues la dignidad humana garantizada en la Constitución es intangible respecto del inculpado y porque esa dignidad prohíbe degradar a un individuo a un objeto involuntario. 
Por otro lado, la Organización de los Estados Americanos (2016) en la Convención Americana sobre Derechos Humanos, establece en:

Artículo 8. Garantías judiciales

Numeral 2. Toda persona inculpada de delito tiene derecho a que se presuma su inocencia mientras no se establezca legalmente su culpabilidad. Durante el proceso, toda persona tiene derecho, en plena igualdad, a las siguientes garantías mínimas:

Literal g. derecho a no ser obligado a declarar contra sí mismo ni a declararse culpable, y

Dicho articulado, busca asimismo equilibrar el interés del Estado en ejercer el ius puniendi y el derecho del individuo a no ser condenado por sus propias declaraciones, además también es partida de nacimiento de un derecho protector, que los constituye el derecho a guardar silencio o derecho a callar, que precisamente es un derecho instrumental de la prohibición de la autoincriminación y del derecho de defensa, que a su vez, también los es del debido proceso.

Es necesario aclarar que, a pesar de que suelen equipararse, el derecho a la no autoincriminación y el derecho a guardar silencio, no son equivalentes, están íntimamente vinculados, pero son dos instituciones jurídicas diferentes. Así el derecho a la no autoincriminación garantiza a no ser obligado a declarar contra sí mismo, y el derecho de guardar silencio, a no responder contra sí mismo o contra otro, a abstenerse de responder sobre interrogatorios investigativos y declaraciones.

Por tanto, es de gran polémica y cuestión de debate genera el derecho a guardar silencio, ya que al ser una garantía, se entiende que es favorable para el procesado en su situación jurídica, más en la aplicación no es así, porque aquella persona que dentro de la primera audiencia de juzgamiento, primera instancia, decide por estrategia del defensor o como ya habíamos mencionado antes, por no incurrir en errores o contradicciones, acogerse al derecho al silencio, creándose así una situación vulnerable para el procesado ya que al haber obtenido una sentencia nada puede hacer o testificar a su favor.

Al finalizar, es bueno aclarar que los abogados por ser conocedores de la ley y sabiendo que el espíritu de esta es alcanzar el bien común y el orden social, confían 
su criterio y la responsabilidad de sus casos en las garantías y principios que el ordenamiento jurídico establecido y en plena vigencia así lo determina, teniendo que enfrentar una realidad adversa al ver que los casos en los que por estrategia de defensa deciden aplicar el derecho al silencio de su defendido, no obtienen los resultados esperados, generándose así inconformidad con las resoluciones judiciales, por lo que en algunos casos es necesario, acudir, reclamar o apelar ante una autoridad superior, lo que produce que se creen nuevos presupuestos tanto de tiempo como económicos.

\section{FINANCIAMIENTO}

No monetario.

\section{AGRADECIMIENTO}

A la Universidad Regional Autónoma de los Andes, Quevedo, Ecuador, por motivar el desarrollo de la Investigación.

\section{REFERENCIAS}

Asamblea Nacional Constituyente de la República del Ecuador, (2008). Constitución de la República del Ecuador. Montecristi. Registro Oficial 449 de 20-oct-2008. Recuperado de https://n9.cl/sia

Benavides-Benalcázar, M. (2019) La reparación integral de la víctima en el proceso penal. Rev. Int. Investig. Cienc. Soc. 15(2), 279-317. Recuperado de: https://n9.cl/ls057

Corte Constitucional del Ecuador (2014). Sentencia № 005-16-SEP-CC caso № 1221 14-EP, CN (Corte Constitucional del Ecuador). Recuperado de: https://n9.cl/unikf

Gutiérrez Campoverde, H., Cantos Ludeña, R. y Durán Ocampo, A. (2019). Vulneración del debido proceso en el procedimiento penal abreviado. Revista Universidad y Sociedad, 11(4), 414-423. Recuperado de: https://n9.cl/v9alm 
Revista Interdisciplinaria de Humanidades, Educación, Ciencia y Tecnología

Año VII. Vol. VII. N¹. Edición Especial. 2021

Hecho el depósito de ley: pp201602FA4721

ISSN-L: 2542-3029; ISSN: 2610-802X

Universidad Nacional Experimental Francisco de Miranda (UNEFM). Santa Ana de Coro. Venezuela

Pedro Pablo Perlaza-Espinoza; Luis Antonio Rivera-Velasco; Orlando Iván Ronquillo-Riera

Organización de los Estados Americanos (2016) Convención Americana Sobre Derechos Humanos. $1^{\text {a }}$ edición: Buenos Aires. Argentina. Recuperado de: https://n9.cl/s8p7a

Rodríguez Camacho, M. (2018). La defensa penal eficaz como garantía del debido proceso en Ecuador. Universidad y Sociedad, 10(1), 33-40. Recuperado de: https://n9.cl/04h99

(C2021 por los autores. Este artículo es de acceso abierto y distribuido según los términos y condiciones de la licencia Creative Commons Atribución-NoComercial-Compartirlgual 4.0 Internacional (CC BY-NC-SA 4.0)

(https://creativecommons.org/licenses/by-nc-sa/4.0/). 